Article

\title{
Effect of Rootstock and Harvesting Period on the Bioactive Compounds and Antioxidant Activity of Two Orange Cultivars ('Salustiana' and 'Sanguinelli') Widely Used in Juice Industry
}

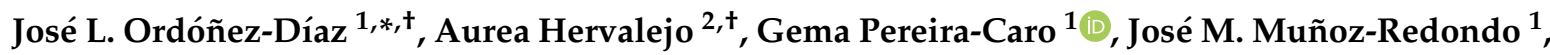 \\ Estefanía Romero-Rodríguez ${ }^{2}$, Francisco J. Arenas-Arenas ${ }^{2}$ and José M. Moreno-Rojas ${ }^{1, *}$ (i) \\ 1 Department of Food Science and Health, Andalusian Institute of Agricultural and Fisheries Research and \\ Training (IFAPA), Avenida Menendez-Pidal, SN, 14004 Córdoba, Spain; \\ mariag.pereira@juntadeandalucia.es (G.P.-C.); josem.munoz.redondo@juntadeandalucia.es (J.M.M.-R.) \\ 2 Department of Agri-Food Engineering and Technology, Andalusian Institute of Agricultural and Fisheries \\ Research and Training (IFAPA), Ctra Sevilla-Cazalla de la Sierra Km. 12,2, 41200 Sevilla, Spain; \\ aurea.hervalejo@juntadeandalucia.es (A.H.); estefania.romero.r@juntadeandalucia.es (E.R.-R.); \\ fjose.arenas@juntadeandalucia.es (F.J.A.-A.) \\ * Correspondence: josel.ordonez@juntadeandalucia.es (J.L.O.-D.); \\ josem.moreno.rojas@juntadeandalucia.es (J.M.M.-R.) \\ + These authors contributed equally to this work.
}

Received: 2 September 2020; Accepted: 23 September 2020; Published: 26 September 2020

\begin{abstract}
Oranges are a rich source of bioactive compounds with recognized benefits for human health. To guarantee high quality and production levels, citrus farms usually employ the combination of selected cultivars with well adapted rootstocks. This study analyzes the impact of four different citrus rootstocks (Forner-Alcaide no.5, 'Cleopatra mandarin', Citrus volkameriana and Carrizo citrange) on the bioactive compounds and antioxidant activity of two orange cultivars ('Salustiana' and 'Sanguinelli') widely used in the orange juice industry. For the hydrophilic fraction, the phenolic compound, anthocyanin, and organic acid profiles were determined by HPLC-DAD-HRMS, and the antioxidant activity by ABTS, DPPH, and ORAC assays. Besides, the total carotenoids and ABTS concentrations were calculated for the hydrophobic fraction. A set of three flavanones, one flavone, and eight anthocyanins were tentatively identified and quantified in the orange cultivars tested. The predominant phenolic compounds obtained in both orange cultivars were hesperidin and narirutin, while cyanidin-3-O-(6"-malonyl) glucoside followed by cyanidin-3-O-rutinoside and cyanidin-3-O-glucoside were the main anthocyanins found in the 'Sanguinelli' cultivar. Citric acid, followed by malic, oxalic, and ascorbic acids were the main organic acids. The higher amount of antioxidant compounds was found in fruit from the Forner-Alcaide no. 5 rootstock. These results indicate that Forner-Alcaide n.5 affects positively the phenolic and organic acid composition and the antioxidant capacity of 'Sanguinelli' and 'Salustiana' cultivars, and is therefore a good option for the sector based on the healthy promoting properties.
\end{abstract}

Keywords: bioactive compounds; anthocyanins; phenolic compounds; food quality; organic acids; antioxidants; pigmented orange; rootstocks; harvesting period; HPLC

\section{Introduction}

Orange juice is the most consumed fruit beverage in the world due to its organoleptic characteristics and health-promoting properties. Currently, due to modern lifestyles, consumers in developed countries 
are replacing the consumption of fresh orange fruit with transformed juices, but continue to demand convenient, healthy, and nourishing products [1,2]. In this context, the consumption of premium orange juice is a good alternative because they are products with a high added value obtained directly from fresh fruits and stabilized by mild heat treatments [3].

Although, the consumption of fruit is associated with a potential prevention of various human oxidative stress-related and degenerative diseases, the relationship between dietary antioxidants and redox balance is still under investigation [4-7]. Oranges are a natural source of antioxidant and bioactive compounds, such as organic acids, phenolic compounds, and carotenoids [8]. In oranges, citric acid is the most important organic acid, followed by malic and ascorbic acids [9]. The organic acid composition in oranges is important as it contributes to their antioxidant capacity and affects their sensory properties. Besides, oranges and other citrus fruits have high concentrations of phenolics and flavonoids, mainly linked to the flavanones group [10]. Consuming foods with a high phenolic compound content is known to be beneficial due to their links with the prevention of human illnesses, such as cancer, diabetes, cardiovascular diseases, and neurological disorders, in addition to the antiviral activity of these compounds [5,11-13]. The phenolic compounds in orange juice play an important role in its sensory quality and, moreover, contribute to its color, bitterness, astringency, antioxidant activity, and flavor [14]. However, these compounds are not distributed evenly throughout the fruit, concentrations being higher in the solid parts [15]. The carotenoids in citrus fruits are rather complex and more than 110 different carotenes and xanthophylls have been identified. These compounds greatly contribute to the external and internal coloring of oranges, which can influence consumer perception and acceptance [16,17]. However, carotenoid content is higher in the peel than in the pulp, reaching 70\% of the total [17]. Overall, the quality of oranges is determined by different factors, such as variety or cultivar, culture conditions, rootstock, or the fruit ripening stage $[18,19]$.

The orange juice industry traditionally selects quality oranges with a high juice yield and optimum organoleptic characteristics, such as high sweetness (total soluble solids), a low content of limonin, and a balanced Total Solid Soluble (TSS)/Titratable acidity (TTA) ratio. Furthermore, in recent years, greater importance has been placed on color characteristics [20-22]. In this context, 'Salustiana' is one of the most important common orange (non-pigmented) cultivars used for making orange juices in Spain [23]. On the other hand, pigmented orange cultivars have been gaining importance in the orange juice industry as they provide an attractive and intense color as well as contributing to the concentration of bioactive compounds. These pigmented orange cultivars contain high levels of anthocyanins, natural red pigments, and have high potential health benefits [24,25]. The main pigmented orange cultivars in the Mediterranean area (Southern Italy and Spain) are 'Sanguinelli' and 'Tarocco' [26].

Traditionally, the use of citrus rootstocks is common in citriculture since they improve the adaptability of plantations to different issues like biotic and abiotic stresses. However, the use of different citrus rootstocks can significantly influence the production and have an important impact on the final chemical composition of the same orange fruit cultivar [18,27]. Besides, the rootstock can cause changes in fruit ripening and the harvesting period, allowing fresh fruit to be produced over a longer period [18,27], which is an interesting factor to take into account as it provides flexibility to farmers, avoiding production peaks and spreading the harvesting period over more months, this being a good alternative for the juice industry.

The aim of this study was to evaluate the composition of bioactive compounds and antioxidant capacity of 'Salustiana' and 'Sanguinelli' orange cultivars grafted on four different citrus rootstocks, and the potential interest to the citrus industry and consumers. Moreover, we evaluated the influence of the intra-year variation of those compounds during the harvesting period (from December to April) on the orange juice quality in two consecutive seasons (2016/2017 and 2017/2018). 


\section{Materials and Methods}

\subsection{Chemicals and Reagents}

Formic acid (FA), phosphoric acid (85\%), acetone, LC-MS (Liquid Chromatography Mass Spectrometry) grade dichloromethane, LC-MS grade acetonitrile, LC-MS grade ethanol, and LC-MS grade methanol were obtained from Panreac (Barcelona, Spain). Organic acid, including citric, succinic, fumaric, oxalic, malic, tartaric and ascorbic acids, $\beta$-carotene, and cyanidin- 3-O-glucoside were obtained from Sigma-Aldrich (Steinheim, Germany). Hesperetin-7-O-rutinoside (hesperidin), 4'-O-methylnaringenin-7-O-rutinoside (didymin), and narigenin-7-O-rutinoside (narirutin) were acquired from Extrasyntheses (Genay, France). 2,2'-azino-bis(3-ethylbenzothiazoline-6-sulfonic acid) diammonium salt (ABTS), 2,2-diphenyl- 1-picrylhydrazyl (DPPH), 2,2'-diazo-bis-amidinepropanedihydrochloride (AAPH), trolox (6-hydroxy-2,5, 7,8 tetramethylchroman-2-carboxylic acid), fluorescein, potassium hydroxide, sodium hydroxide, and potassium persulfate were purchased from Sigma-Aldrich (Steinheim, Germany). Ultrapure water was obtained from a Milli-Q water purification system (Millipore, Bedford, MA, USA).

\subsection{Experimental Plot}

Two orange cultivars were selected for this study: 'Salustiana' (Citrus sinensis (L.) Osbeck cv. Salustiana) and 'Sanguinelli' (Citrus sinensis (L.) Osbeck cv. Sanguinelli).

'Salustiana' is a cultivar of the group of white oranges with a high juice content and sweet flavor. It is suitable for both the fresh market and processing into juice since it contains low limonin contents. It is a mid-season orange cultivar, normally harvested from mid-December to the end of March in Spain [23]. 'Sanguinelli' is a pigmented orange cultivar with a high juice content and excellent flavor and smell. It is very popular in Italy due to its internal and external color and fresh flavor [28]. All these characteristics give it commercial appeal. 'Sanguinelli' is also a mid-season orange cultivar, normally harvested from January to March in Spain.

The cultivars under study were cultivated in the south of Spain (Seville, Andalusia) and were nine years old at the beginning of the experiment. Both cultivars were grafted on four citrus rootstocks, Carrizo citrange (CA; Citrus sinensis $\times$ Poncirus trifoliata), 'Cleopatra mandarin' (Citrus reshni; CL), Citrus volkameriana (VK), and Forner-Alcaide no.5 (FA5; 'Cleopatra mandarin' $\times$ Poncirus trifoliata). The experimental design was a randomized block with three replications and an experimental unit of four trees per combination cultivar and rootstock.

In Spain, Carrizo citrange is the main rootstock used in citrus, over $80 \%$ of nursery production [29]. However, Carrizo citrange (a standard growing citrus rootstock) due to its susceptibility to lime induced chlorosis and salinity [14] is unsuitable for many soils of the Mediterranean area. In this context, the use of different conventional citrus rootstocks, such as 'Cleopatra mandarin' and Citrus volkameriana (standard growing citrus rootstocks), and Forner-Alcaide no.5 (substandard citrus rootstock) may offer a better response to those abiotic stresses [14,29]. Additional information about rootstock can be found in the Supplementary Materials Table S1.

Local climate is the Mediterranean with an average temperature of $18.1^{\circ} \mathrm{C}, 586.7 \mathrm{~mm}$ annual rainfall and $1292.4 \mathrm{~mm}$ reference evapotranspiration (ET0). The soil presents a loam texture (25\% clay, $32 \%$ sand, and $43 \%$ silt), with $1.0 \%$ organic matter content, a pH of $8.0,4.8 \%$ active $\mathrm{CaCO}_{3}$, and $0.12 \mathrm{dS} / \mathrm{m}$ electrical conductivity in a 1:5 soil water extract Additional information about temperature, humidity, precipitation, solar radiation, and evapotranspiration can be found in Table S2.

Standard cultural practices were applied, including drip irrigation and hand pruning annually after harvest. Irrigation was applied by two drip-lines in each tree row, with $2.20 \mathrm{~L} / \mathrm{h}$ drippers every $60 \mathrm{~cm}$. Seasonal water requirements were calculated based on reference evapotranspiration $\left(\mathrm{ET}_{0}\right)$ and the citrus crop coefficient $(\mathrm{Kc})[30]$.

The trees were fertilized by a fertigation system with an optimal fertilizer program according to the procedure established by Quiñones et al. [31]. 


\subsection{Samples}

The orange samples were harvested in two consecutive growing seasons, 2016/2017 and 2017/2018. Several fruit samplings were conducted monthly from December ('Salustiana') and January ('Sanguinelli') to April to establish the effect of the harvesting period on fruit quality parameters. Thus, a total of 5 samples of 'Salustiana' and 4 of 'Sanguinelli' were taken to evaluate the intra-year harvesting date. These samples comprised of 5 fruits collected from each tree from each orange cultivar, rootstock, and experimental block ( $N$ 'Salustiana': 300 and N 'Sanguinelli': 240 per year).

The orange samples harvested during this research reached the minimum requirements of the orange juice industry, such as high levels of TSS $\left(>10^{\circ}\right.$ Brix) and high juice content $(>50 \%)$. Table S3 shows the information about diameter, content of juice, and TSS of both cultivars grafted on the four rootstocks evaluated.

\subsection{Sample Preparation}

Prior to analysis, the peel was separated from the pulp. Fresh pulp was ground (Sammic Cutter SK-3, Gipuzkoa, Spain) and homogenized (Ultraturrax ${ }^{\circledR}$, Stauten, Germany). Aliquots of the homogenized pulp were used for the extraction of the analytes of interest with different methods. The samples were stored at $-80^{\circ} \mathrm{C}$ until analysis.

\subsubsection{Hydrophilic Extraction}

The extraction of compounds of hydrophilic fractions was carried out using a mixed solution of deionized water and methanol (20:80, v/v) acidified with $1 \%$ formic acid. Thus, $0.5 \mathrm{mg}$ of homogenized sample was extracted with $1 \mathrm{~mL}$ of the solvent solution before being sonicated for $10 \mathrm{~min}$ and centrifuged at 15,000 rpm for $15 \mathrm{~min}$. The supernatant was collected and pellet was re-extracted using the same protocol. The samples were transferred into vials and stored at $-80^{\circ} \mathrm{C}$ until their analysis.

\subsubsection{Lipophilic Extraction}

The extraction of the lipophilic fraction and saponification was performed following a method previously reported with some modifications [32]. The samples were stored at $-80^{\circ} \mathrm{C}$ until their analysis.

\subsubsection{Organic Acids Extraction}

The extraction of organic acids was performed following a previously reported method with some modifications [33]. Briefly, $0.5 \mathrm{mg}$ of homogenized samples were extracted with $1 \mathrm{~mL}$ of cold deionized water acidified with $3 \%$ phosphoric acid. Then, it was sonicated for $10 \mathrm{~min}$ and centrifuged at 15,000 rpm for $15 \mathrm{~min}$. The supernatant was collected and the pellet was re-extracted using the same protocol. Both supernatants were pooled together in amber glass vials and analyzed in the UHPLC-DAD (Diode Array Detector) system. Owing to the instability of the organic acid extracts, these were measured immediately after extraction.

\subsection{Antioxidant Activity Evaluation}

Antioxidant activity was evaluated using three different methodologies: ABTS, DPPH, and ORAC (Oxygen Radical Absorbance Capacity) assays. These analyses were measured using a Synergy HTX Multi-Mode Microplate Reader (Biotek Instruments, Winooski, VT, USA).

\subsubsection{ABTS Assay}

The free radical scavenging activity was determined using the ABTS decoloration method [34] with some modifications of Madrona et al. [35]. This method was used to determine the antioxidant activity in the hydrophilic and lipophilic extracts. The antioxidant activity was expressed as $\mathrm{mg}$ of Trolox equivalents per $100 \mathrm{~g}$ of fresh sample (mg TE/100 g FW). Each value is the average of three determinations. 


\subsubsection{DPPH Assay}

Free radical DPPH (1,1-diphenyl-2-picryl-hydrazyl) scavenging activity was measured in the hydrophilic extract following the methods previously described by Sánchez-Moreno [36]. The antioxidant activity was expressed as $\mathrm{mg}$ of Trolox equivalents per $100 \mathrm{~g}$ of fresh sample (mg TE/100 $\mathrm{g}$ FW). Each value is the average of three measurements.

\subsubsection{ORAC Assay}

The oxygen radical scavenging activity in the hydrophilic extract was performed by the ORAC assay according to the method previously published by Madrona et al. [35]. ORAC values are expressed as $\mu \mathrm{M}$ Trolox equivalents per $100 \mathrm{~g}$ of fresh sample ( $\mu \mathrm{M}$ TE/100 $\mathrm{g} F W$ ). Each value is the average of three measurements.

\subsection{Total Carotenoids}

The total carotenoids measurements were performed following the method previously published by Alzate et al. [37]. The lipophilic extract was reconstituted using dichloromethane and placed in a flat bottom 96-well quartz microplate with a $300 \mu \mathrm{L}$ well capacity (Hellma Analytics, Plainview, NY, USA). The absorbance was measured at $450 \mathrm{~nm}$ in a Synergy HTX Multi-Mode Microplate Reader (Biotek Instruments, Winooski, VT, USA). The total carotenoids were expressed as mg of $\beta$-carotene equivalents per $100 \mathrm{~g}$ of fresh sample $(\mathrm{mg} \beta \mathrm{C} / 100 \mathrm{~g} \mathrm{FW})$. All measurements were performed in triplicate.

\subsection{UHPLC-DAD-HRMS Analysis}

The identification and quantification of the phenolic (and anthocyanin) compounds and organic acids in the orange samples were performed using an UHPLC-DAD-HRMS (High Resolution Mass Spectrometry) mass spectrometer system (Thermo Scientific, San José, CA, USA) comprising of a UHPLC pump, a DAD detector scanning from 200 to $600 \mathrm{~nm}$, and an autosampler operating at $4{ }^{\circ} \mathrm{C}$ (Dionex Ultimate 3000 RS, Thermo Corporation, Waltham, MA, USA).

\subsubsection{Phenolic Compounds Analysis}

The phenolic compounds profile was analyzed according to the method published by Pereira-Caro et al. [10] with some modifications. Briefly, the separation of phenolic compounds was carried out with a C18 Kinetex RP column $(150 \mathrm{~mm} \times 4.6 \mathrm{~mm}, 5 \mu \mathrm{m})$ from Phenomenex (Torrance, CA, USA). The injection volume was $10 \mu \mathrm{L}$ and the separation was obtained at a flow rate of $1 \mathrm{~mL} / \mathrm{min}$ at $40{ }^{\circ} \mathrm{C}$ with a $30 \mathrm{~min}$ gradient of $10-45 \%$ of $0.1 \%$ acidic methanol in $0.1 \%$ aqueous formic acid. Detection was performed by a diode array detector set at $280 \mathrm{~nm}$. The phenolic compounds were identified by comparing them with the retention time and mass spectra of organic acid standards and quantified on the basis of the chromatographic peak areas acquired at $280 \mathrm{~nm}$ and expressed relative to standards.

\subsubsection{Anthocyanin Analysis}

The analysis of the anthocyanin profile was carried out following a previous publication by Hornedo-Ortega et al. [38] with some modifications. Briefly, the separation of anthocyanin was performed on a Zorbax SB-C18 RRHD column $(100 \mathrm{~mm} \times 2.1 \mathrm{~mm}, 1.8 \mu \mathrm{m})$ from Agilent (Santa Clara, CA, USA) preceded by a guard precolumn of the same stationary phase and maintained at $40{ }^{\circ} \mathrm{C}$. The mobile phases, A: water and formic acid 90:10 $(v / v)$ and B: acetonitrile and formic acid 90:10 $(v / v)$, were pumped at a flow rate of $0.3 \mathrm{~mL} / \mathrm{min}$ with an $18 \mathrm{~min}$ gradient. They started at $1 \% \mathrm{~B}$, then rose to $20 \% \mathrm{~B}$ in $10 \mathrm{~min}$, and were maintained for $3 \mathrm{~min}$ before rising to $100 \% \mathrm{~B}$ in $2 \mathrm{~min}$. After that, the column was equilibrated to the previous conditions within $6 \mathrm{~min}$. The injection volume was $2 \mu \mathrm{L}$.

After passing through the flow cell of the PDA detector, the column eluate went directly to an Exactive Orbitrap mass spectrometer (Thermo Scientific, San José, CA, USA) fitted with a heated 
electrospray ionization probe (HESI) operating in the positive ionization mode for the determination of anthocyanin. Full scans were recorded in $\mathrm{m} / \mathrm{z}$ range from 100 to 1000 with a resolution of 50,000 Hz and with a full AGC target of 100,000 charges, using 2 microscans. Analyses were also based on scans with in-source collision-induced dissociation (CID) at $25.0 \mathrm{eV}$. The MS experimental conditions with HESI in positive ionization mode were: capillary temperature of $300^{\circ} \mathrm{C}$, heater temperature of $60^{\circ} \mathrm{C}$, the sheath gas was 20 units, the auxiliary gas was 2 units, and the spray voltage was $4.0 \mathrm{kv}$.

Quality control (QC) samples were applied to assess and verify the analytical process. The QC samples, consisting of a pool of blood orange samples, were injected regularly throughout the run. Data acquisition and processing were carried out using Xcalibur 3.0 software (Thermo Scientific, San José, CA, USA).

Tentative identification of anthocyanins (Table S4) was achieved as follows: (i) by comparing the exact mass and the retention time with available standards and (ii) in the absence of standards, compounds were tentatively identified by comparing the theoretical exact mass and measured accurate mass of the molecular ion and comparison with metabolite databases including Metlin, Phenol Explorer, PubChem, etc. Metabolites having molecular masses within the prespecified tolerance ( $\leq 5 \mathrm{ppm})$ of the query masses were retrieved from these databases.

Anthocyanins were quantified using the areas of their chromatographic peaks by selecting the theoretical exact mass of the molecular ion by comparison to a cyanidin 3-O-glucoside calibration curve.

\subsubsection{Organic Acids Analysis}

The analysis of the organic acids profile was carried out following the method previously described by Moreno-Ortega et al. [39]. Briefly, the separation was performed on a Synergi Hydro-RP column $(250 \mathrm{~mm} \times 4.6 \mathrm{~mm}, 4 \mu \mathrm{m}$ ) from Phenomenex (Torrance, CA, USA). The injection volume was $10 \mu \mathrm{L}$ and the separation was carried out at a flow rate of $0.7 \mathrm{~mL} / \mathrm{min}$ for $20 \mathrm{~min}$ at $22{ }^{\circ} \mathrm{C}$ with an isocratic program. The mobile phase consisted of a $20 \mathrm{mM}$ potassium phosphate. Detection was performed by a diode array detector set at $254 \mathrm{~nm}$ for ascorbic acid and $220 \mathrm{~nm}$ for the rest of organic acids. They were all identified by comparing the retention time and the maximum wavelength with pure organic acid standards. The quantification was performed using standards references of $0.1-3000.0 \mathrm{mg} / \mathrm{L}$ calibration curves.

\subsection{Statistical Analysis}

Univariate statistical analyses were performed on the basis of three analytical replicates measured on each sample using the Statistix v. 9.0 software. The data were subjected to an analysis of variance (ANOVA), followed by a comparison of means according to the least significant difference (LSD) test. The level of significance was established at $p<0.05$.

Multivariate analyses were performed using in-house routines based on the mixOmics package [40] built under the R v. 4.0.0 program. A multilevel partial least squares discriminant analysis (ML-PLS-DA) was fitted to evaluate the effect of rootstocks. ML-PLS-DA may be considered as the multivariate extension of a paired $t$-test, which allows for separation of the within treatment variation, in this study the date of sampling, from the total variation owed to the treatment [41]. To reduce the complexity of the model and enable easier interpretation of the results, a previous selection of the most discriminative variables was performed using an iterative procedure based on value importance in projection (VIP) scores, obtained from an initial ML-PLS-DA model, as described in Muñoz-Redondo et al. [42]. The selected variables were then used to build a final ML-PLS-DA model and were considered potential markers of the treatment. The final ability ML-PLS-DA model was assessed using leave-one-out cross-validation and the classification error rate was determined by comparing the predicted class with the real one. The balanced error rate (BER) measured at the Mahalanobis distance was employed as a diagnostic statistic in calibration and validation. 


\section{Results and Discussion}

\subsection{Evaluation of Organic Acids}

The main organic acid in oranges was citric acid, which reached 85-93\% in 'Salustiana' and 83-95\% in 'Sanguinelli' (Table 1) followed by malic, oxalic, and ascorbic acids, in agreement with previous research [9]. Regarding the rootstock, the lowest concentrations of all the organic acids were obtained for VK for the samples from both cultivars, 'Salustiana' and 'Sanguinelli'. Similar results in sweet oranges were previously observed by other authors, showing the important impact of organic acid concentration on fruit quality $[29,43]$. The concentrations found for malic acid were slightly higher in the 'Sanguinelli' samples, where we observed an impact of the rootstock, the samples from FA5 and CL (Table 1) presenting the highest values. Regarding oxalic acid, we observed that the samples from FA5 and CL rootstocks presented the highest concentrations for both cultivars. Regarding ascorbic acid concentrations, we observed a marked influence of the rootstock in the 'Salustiana' orange cultivar, the samples from FA5 showing the highest levels for this compound, followed by CL, while the lowest values were obtained by CA and VK (Table 1). However, this effect was not so marked in the 'Sanguinelli' samples, which showed significant differences between FA5 (highest values) and CL and VK (lowest ones). Other organic acids, such as tartaric, succinic, or fumaric acid, were quantified in lower concentrations. For the 'Salustiana' cultivar, the concentration of tartaric acid was higher for the FA5 and CL rootstocks, whilst the highest values of fumaric acid were found for FA5. In the 'Sanguinelli' samples, the differences in the concentration of tartaric and fumaric acids were less marked, the samples from the VK rootstock presenting the lowest values (Table 1).

Regarding the influence of sampling date during the harvesting period, citric acid showed a similar trend for both 'Salustiana' and 'Sanguinelli', with a decrease in its concentration from the beginning until the end of the period (Table 1). This is important because citric acid plays an important role in the maturity index and acceptability of the product by consumers. This trend during the harvesting period was observed by other authors $[17,44]$. The evolution of malic acid between different sampling dates showed differences in both cultivars (Table 1). Thus, the content of malic acid in the 'Salustiana' oranges had a V-shaped evolution; that is, the highest concentrations were at the beginning (December) and at the end (March and April) of the harvesting period. Meanwhile, the 'Sanguinelli' samples showed the lowest concentrations of citric acid in January, reaching the highest concentration in March, levels then decreasing again in April. On the other hand, the highest concentrations of ascorbic acid were reached at different dates during the harvesting period: January for 'Salustiana' and March for 'Sanguinelli' (Table 1). Different trends were also observed for tartaric acid in the two cultivars. Tartaric acid showed a trend to increase in the 'Salustiana' samples, with the highest values at the end of the harvesting period, whilst in the 'Sanguinelli' samples the highest values were found at the beginning of the harvesting season (January). The negative correlation between ascorbic acid content and the concentration of oxalic and tartaric acid observed in 'Salustiana' may be explained by the ascorbate metabolism observed in plants $[45,46]$. However, this correlation was not so clear for 'Sanguinelli' cultivar. The evolution of fumaric acid during the sampling period was similar in both cultivars (Table 1). Generally, we observed a decrease in most of the organic acids under study at the end of the season. This could be explained by the fact that the fruit used these compounds as respiratory substrates and as carbon skeletons for the synthesis of new compounds [47].

Regarding the harvesting year factor, we observed a significant impact in the content of organic acids for both cultivars, the highest values being obtained in 2018, in particular in the 'Salustiana' oranges (Table 1). 
Table 1. Effect of rootstock, sampling date, and year on organic acid concentration in 'Salustiana' and 'Sanguinelli' cultivars. Organic acids are expressed in $\mathrm{mg} / 100 \mathrm{~g}$ FW.

\begin{tabular}{|c|c|c|c|c|c|c|c|c|c|c|c|c|c|c|c|c|}
\hline \multirow{2}{*}{ 'SALUSTIAN } & \multicolumn{2}{|c|}{ Citric Acid } & \multicolumn{2}{|c|}{ Malic Acid } & \multicolumn{2}{|c|}{ Oxalic Acid } & \multicolumn{2}{|c|}{ Ascorbic Acid } & \multicolumn{2}{|c|}{ Tartaric Acid } & \multicolumn{2}{|c|}{ Succinic Acid } & \multicolumn{2}{|c|}{ Fumaric Acid } & \multicolumn{2}{|c|}{ Total } \\
\hline & & & & & & & & & & & & & & & & \\
\hline \multicolumn{17}{|c|}{ ROOTSTOCK } \\
\hline FA5 & 2003.8 & A & 60.74 & & 64.98 & A & 39.60 & A & 20.07 & A & 19.43 & & 5.77 & A & 2214.3 & A \\
\hline CA & 1929.6 & $\mathrm{AB}$ & 59.67 & & 57.75 & B & 32.98 & C & 18.64 & B & 19.54 & & 5.13 & C & 2123.3 & $\mathrm{AB}$ \\
\hline CL & 1782.6 & BC & 62.37 & & 64.86 & A & 36.16 & B & 20.34 & A & 19.11 & & 5.38 & B & 1990.8 & BC \\
\hline VK & 1723.7 & $\mathrm{C}$ & 62.65 & & 57.14 & B & 31.61 & C & 17.53 & C & 18.34 & & 4.83 & $\mathrm{D}$ & 1915.8 & $\mathrm{C}$ \\
\hline$p$-value & $* *$ & & ns & & $* * *$ & & $* * *$ & & $* * *$ & & ns & & $* * *$ & & $* *$ & \\
\hline \multicolumn{17}{|l|}{ Sampling } \\
\hline December & 2194.7 & A & 68.59 & A & 58.38 & $\mathrm{CD}$ & 35.15 & B & 17.45 & $\mathrm{C}$ & 20.61 & A & 5.86 & A & 2400.8 & A \\
\hline January & 1898.3 & B & 55.17 & C & 60.64 & $\mathrm{BC}$ & 38.08 & A & 17.69 & C & 18.84 & B & 5.83 & A & 2094.5 & B \\
\hline February & 1813.4 & BC & 51.91 & C & 64.28 & $\mathrm{AB}$ & 36.24 & B & 19.28 & B & 19.21 & B & 5.22 & B & 2009.5 & BC \\
\hline March & 1735.2 & $\mathrm{BC}$ & 67.13 & $\mathrm{AB}$ & 67.99 & A & 35.80 & B & 20.02 & B & 18.40 & B & 4.82 & C & 1949.4 & $\mathrm{BC}$ \\
\hline April & 1657.9 & $\mathrm{C}$ & 63.98 & B & 54.62 & D & 30.16 & C & 21.29 & A & 18.46 & B & 4.67 & C & 1851.1 & C \\
\hline$p$-value & $* * *$ & & $* * *$ & & $* * *$ & & $* * *$ & & $* * *$ & & $* * *$ & & $* * *$ & & $* * *$ & \\
\hline \multicolumn{17}{|l|}{ Year } \\
\hline 2017 & 1593.8 & B & 68.45 & A & 70.98 & A & 32.80 & B & 18.53 & B & 17.80 & B & 5.82 & A & 1808.2 & B \\
\hline 2018 & 2126.0 & A & 54.27 & B & 51.38 & B & 37.38 & A & 19.76 & A & 20.41 & A & 4.73 & B & 2313.9 & A \\
\hline$p$-value & $* * *$ & & $* * *$ & & $* * *$ & & $* * *$ & & $* *$ & & $* * *$ & & $* * *$ & & $* * *$ & \\
\hline \multicolumn{17}{|c|}{ 'SANGUINELLI' } \\
\hline \multicolumn{17}{|c|}{ ROOTSTOCK } \\
\hline FA5 & 2020.2 & $\mathrm{AB}$ & 113.80 & A & 72.89 & A & 43.15 & A & 17.78 & A & 9.50 & & 7.04 & A & 2284.3 & A \\
\hline CA & 1954.7 & B & 107.70 & B & 66.92 & B & 41.34 & $\mathrm{AB}$ & 16.15 & $\mathrm{BC}$ & 9.48 & & 6.53 & $\mathrm{BC}$ & 2202.8 & B \\
\hline CL & 2081.6 & A & 111.16 & A & 71.86 & A & 40.62 & B & 16.91 & $A B$ & 9.79 & & 6.85 & $A B$ & 2338.7 & A \\
\hline VK & 1844.9 & $\mathrm{C}$ & 103.36 & $\mathrm{C}$ & 63.70 & B & 40.58 & B & 15.36 & $\mathrm{C}$ & 9.89 & & 6.18 & $\mathrm{C}$ & 2084.0 & $\mathrm{C}$ \\
\hline$p$-value & $* * *$ & & $* * *$ & & $* * *$ & & $*$ & & $* * *$ & & ns & & $* *$ & & $* * *$ & \\
\hline \multicolumn{16}{|l|}{ Sampling } & A \\
\hline February & 2015.6 & B & 119.33 & B & 70.58 & A & 41.56 & B & 15.94 & B & 10.12 & A & 7.42 & A & 2280.5 & B \\
\hline March & 1910.8 & $\mathrm{C}$ & 122.91 & A & 71.72 & A & 44.98 & A & 16.24 & B & 9.97 & A & 6.18 & B & 2182.7 & $\mathrm{C}$ \\
\hline April & 1834.4 & $\mathrm{D}$ & 119.38 & B & 65.28 & B & 40.30 & $\mathrm{BC}$ & 16.26 & B & 9.66 & A & 5.53 & $\mathrm{C}$ & 2090.8 & $\mathrm{D}$ \\
\hline$p$-value & $* * *$ & & $* * *$ & & $*$ & & $* * *$ & & $* *$ & & $* * *$ & & $* * *$ & & $* * *$ & \\
\hline \multicolumn{17}{|l|}{ Year } \\
\hline 2017 & 1807.0 & B & 109.24 & & 66.85 & B & 40.44 & B & 16.67 & & 9.77 & & 7.56 & A & 2057.5 & B \\
\hline 2018 & 2143.6 & A & 108.76 & & 70.83 & A & 42.40 & A & 16.43 & & 9.57 & & 5.74 & B & 2397.4 & A \\
\hline$p$-value & $* * *$ & & ns & & $*$ & & $* *$ & & ns & & ns & & $* * *$ & & $* * *$ & \\
\hline
\end{tabular}

Mean values with different letters in the same column present significant differences. Significant level: $\mathrm{ns}=$ not significant. ${ }^{*}=p<0.05 .{ }^{* *}=p<0.01 .{ }^{* * *}=p<0.001$. Values are expressed as means of rootstocks, sampling date, and year. 


\subsection{Evaluation of Bioactive Compounds in Hydrophilic Extracts}

\subsubsection{Phenolic Compounds Profile}

The main phenolic compounds determined and quantified were hesperidin, narirutin, vicenin-2, and didymin (Table 2). In agreement with the literature [17,48,49], we found that hesperidin was the main flavanone and it was quantified in similar concentrations for both cultivars (Table 2). A similar flavonoid composition pattern between different varieties of oranges have been previously reported and found in other Citrus species like mandarin (Citrus reticulata) and lemon (Citrus lemon) [48]. Although hesperidin is present in high concentrations, it does not contribute to the final taste of the orange juice because it is a tasteless compound [50]. We found that narirutin was the second flavanone in oranges regarding concentration (Table 2), in line with previous research [24,51]. In general, the total concentrations of phenolic compounds were between 85 and $115 \mathrm{mg} / 100 \mathrm{~g}$ of fresh weight. These results are in accordance with previous studies $[51,52]$.

Table 2. Effect of rootstock, sampling date, and year on phenolic compound concentration in 'Salustiana' and 'Sanguinelli' cultivars. Phenolic compounds are expressed in mg/100 g FW.

\begin{tabular}{|c|c|c|c|c|c|c|c|c|c|c|}
\hline & \multicolumn{2}{|c|}{ Hesperidin } & \multicolumn{2}{|c|}{ Narirutin } & \multicolumn{2}{|c|}{ Vicenin-2 } & \multicolumn{2}{|c|}{ Didymin } & \multicolumn{2}{|c|}{ Total } \\
\hline \multicolumn{11}{|c|}{ ROOTSTOCK } \\
\hline FA5 & 74.39 & & 14.70 & A & 5.11 & $\mathrm{~A}$ & 5.49 & B & 99.68 & \\
\hline CA & 77.37 & & 14.72 & A & 5.00 & A & 5.63 & B & 102.73 & \\
\hline CL & 77.49 & & 14.71 & A & 5.07 & A & 6.37 & A & 103.64 & \\
\hline VK & 76.91 & & 13.08 & B & 4.55 & B & 5.51 & B & 100.04 & \\
\hline$p$-value & ns & & $* *$ & & $* * *$ & & $* * *$ & & ns & \\
\hline \multicolumn{11}{|l|}{ Sampling } \\
\hline December & 64.67 & $\mathrm{D}$ & 11.71 & $\mathrm{D}$ & 3.90 & $\mathrm{D}$ & 3.85 & $\mathrm{D}$ & 84.12 & $\mathrm{D}$ \\
\hline January & 72.27 & $\mathrm{C}$ & 13.78 & C & 4.53 & $\mathrm{C}$ & 4.79 & $\mathrm{C}$ & 95.36 & $\mathrm{C}$ \\
\hline February & 79.44 & B & 14.96 & B & 4.81 & $\mathrm{C}$ & 5.80 & B & 105.01 & B \\
\hline March & 84.85 & A & 16.08 & A & 5.90 & A & 7.23 & A & 114.06 & A \\
\hline April & 81.47 & $\mathrm{AB}$ & 14.99 & $\mathrm{AB}$ & 5.52 & B & 7.09 & A & 109.07 & $\mathrm{AB}$ \\
\hline$p$-value & $* * *$ & & $* * *$ & & $* * *$ & & $* * *$ & & $* * *$ & \\
\hline \multicolumn{11}{|l|}{ YEAR } \\
\hline 2017 & 71.87 & B & 14.02 & & 5.02 & & 6.00 & A & 96.9 & B \\
\hline 2018 & 81.21 & A & 14.59 & & 4.84 & & 5.51 & B & 106.15 & A \\
\hline$p$-value & $* * *$ & & ns & & ns & & $* *$ & & $* * *$ & \\
\hline \multicolumn{11}{|c|}{ ‘SANGUINELLI' } \\
\hline \multicolumn{11}{|c|}{ ROOTSTOCK } \\
\hline FA5 & 78.13 & & 5.85 & A & 6.86 & A & 2.47 & $\mathrm{AB}$ & 93.32 & \\
\hline CA & 74.92 & & 5.89 & A & 6.30 & B & 2.31 & $\mathrm{BC}$ & 90.78 & \\
\hline CL & 76.04 & & 5.68 & A & 6.42 & B & 2.65 & A & 89.75 & \\
\hline VK & 77.04 & & 4.78 & B & 5.78 & $\mathrm{C}$ & 2.15 & C & 89.43 & \\
\hline$p$-value & ns & & $* * *$ & & $* * *$ & & $* * *$ & & $\mathrm{~ns}$ & \\
\hline \multicolumn{11}{|l|}{ Sampling } \\
\hline February & 85.16 & A & 6.05 & $\mathrm{~A}$ & 6.82 & $\mathrm{~A}$ & 2.57 & B & 100.60 & A \\
\hline March & 76.81 & B & 5.67 & $\mathrm{AB}$ & 6.49 & B & 2.38 & B & 91.35 & B \\
\hline April & 72.25 & $\mathrm{BC}$ & 5.23 & C & 6.72 & $\mathrm{AB}$ & 3.02 & A & 87.22 & BC \\
\hline$p$-value & $* * *$ & & $* * *$ & & $* * *$ & & $* * *$ & & $* * *$ & \\
\hline \multicolumn{11}{|l|}{ Year } \\
\hline 2017 & 81.51 & A & 5.80 & A & 6.44 & & 2.41 & & 96.16 & A \\
\hline 2018 & 71.55 & B & 5.31 & B & 6.24 & & 2.38 & & 85.48 & B \\
\hline$p$-value & $* * *$ & & $* *$ & & $\mathrm{~ns}$ & & ns & & $* * *$ & \\
\hline
\end{tabular}

Mean values with different letters in the same column present significant differences. Significant level: $\mathrm{ns}=$ not significant. ${ }^{*}=p<0.05 .{ }^{* *}=p<0.01 .{ }^{* * *}=p<0.001$. Values are expressed as means of rootstocks, sampling date, and year.

Concerning rootstocks, we did not observe a relevant impact of this factor for the total concentration of phenolic compounds. No significant differences were observed for both 'Salustiana' and 'Sanguinelli'. The major contribution was made by the main flavanone, hesperidin, following the same trend in both cultivars (Table 2). Narirutin and vicenin-2 were higher in FA5, CA, and CL than VK in both 
cultivars, showing an important influence of the rootstock where the orange cultivar is grafted. Didymin was quantified in higher concentrations in CL than the other rootstocks in the 'Salustiana' oranges. The difference in the content of didymin was less marked in the 'Sanguinelli' cultivar, although higher concentrations were observed in CL than in CA and VK (Table 2). The influence of the rootstocks and the changes in the profile of secondary metabolites, including flavonoids, were observed in previous research in the mandarin (Citrus reticulata) [53].

Changes in the phenolic compounds were observed during the harvesting period. The highest values for total phenolic compounds content in the samples were reached at the end of the harvesting period (February-April) for 'Salustiana', while a different behavior was found for the 'Sanguinelli' samples, for which we obtained the highest value on the second sampling date (February), then theses values decreased until April (Table 2). These changes in the concentrations of bioactive compounds during the harvesting period have been observed in citrus cultivars in the literature [18,54]. An increase was found in the concentration of flavanones in the 'Salustiana' oranges, including hesperidin, narirutin, and didymin, the highest levels being reached on the last sampling dates (Table 2). In the 'Sanguinelli' oranges, this trend was only observed for didymin.

Regarding harvesting years, the concentrations of different phenolic compounds were heterogeneous and without clear trends (Table 2). Hesperidin was higher in the first harvesting year and didymin in the second year in the 'Salustiana' oranges. On the other hand, hesperidin and narirutin were higher in the first year in the 'Sanguinelli' samples.

\subsubsection{Anthocyanin Compounds Profile}

A total of eight anthocyanins were tentatively identified (Table 3). In general, the observed anthocyanin profile was characterized by glycosides of cyanidin and, to a lesser extent, glycosides of delphinidin and peonidin. These data are in agreement with other authors $[55,56]$. Thus, we found that cyanidin-3-O-(6"-malonyl) glucoside, cyanide 3-O-glucoside, and cyanide 3-O-rutinoside were the main compounds, in agreement with other publications $[55,57]$. The total anthocyanins content was between 10 and $12 \mathrm{mg} / 100 \mathrm{~g}$ FW.

Regarding rootstocks, the samples from the FA5 and CL rootstocks showed the highest total anthocyanin content values. Considering the anthocyanin profile, significant differences were observed between the evaluated rootstocks (Table 3). Thus, the anthocyanins quantified showed variable levels in each rootstock, showing a high influence in the final concentration. The orange samples from the FA5 and CL rootstocks had the highest concentrations of the main cyanidin derivatives, including cyanidin-3-O-(6"-malonyl) glucoside, cyanidin 3-O-glucoside, and cyanidin 3-O-rutinoside (Table 3). Cyanidin 3,5-O-diglucoside was significantly higher in the FA5, CA, and VK rootstocks.

The concentration of anthocyanins increased during the harvesting period, peaking for the sampling in March (Table 3). Thus, most anthocyanins showed similar trends during the first stages, their concentrations increasing progressively. Changes in the content of anthocyanin during the harvesting period have been previously reported by different researchers $[26,58]$. It should be highlighted that, while the levels of other anthocyanins increased, several of the main ones presented decreased in their concentrations by the end of the sampling period (April), such as cyanidin 3-O-(6"-malonyl) glucoside and cyanidin 3-O-glucoside. This resulted in a decrease in the total content of anthocyanins at the end of the harvesting period as those compounds are the major contributors. This decrease has been observed in the literature [56,58]

Furthermore, differences in the anthocyanin profile were observed between the two harvesting years evaluated. The first year presented a higher concentration of total anthocyanins. The concentration of cyanidin 3-O-(6"-malonyl) glucoside was significantly higher in the first year $(13 \%)$, cyanidin 3-O-glucoside in the second (around 25\%), whilst cyanidin 3-O-rutinoside remained stable. These differences in the anthocyanin profile may be due to the ability of the Citrus plant to modulate the activation of reactions involved in the anthocyanin biosynthetic pathways depending on the specific needs of the plant [55]. 
Table 3. Effect of rootstock, sampling date, and year on anthocyanin concentration in 'Sanguinelli' cultivars. Anthocyanins are expressed in mg/100 g FW.

\begin{tabular}{|c|c|c|c|c|c|c|c|c|c|c|c|c|c|c|c|c|c|c|}
\hline ROOTSTOCI & \multicolumn{2}{|c|}{$\begin{array}{c}\text { Cyanidin } \\
\text { 3-O-(6"-Malonyl) } \\
\text { Glucoside }\end{array}$} & \multicolumn{2}{|c|}{$\begin{array}{l}\text { Cyanidin } \\
\text { 3-O-Glucoside }\end{array}$} & \multicolumn{2}{|c|}{$\begin{array}{c}\text { Cyanidin } \\
\text { 3-O-Rutinoside }\end{array}$} & \multicolumn{2}{|c|}{$\begin{array}{c}\text { Cyanidin } \\
\text { 3,5-O-Diglucoside }\end{array}$} & \multicolumn{2}{|c|}{$\begin{array}{l}\text { Cyanidin } \\
\text { 3-O-Sophoroside }\end{array}$} & \multicolumn{2}{|c|}{$\begin{array}{c}\text { Cyanidin } \\
\text { 3-O-(6"-acetyl) } \\
\text { Glucoside }\end{array}$} & \multicolumn{2}{|c|}{$\begin{array}{l}\text { Delphinidin } \\
\text { 3-O-Glucoside }\end{array}$} & \multicolumn{2}{|c|}{$\begin{array}{l}\text { Peonidin } \\
\text { 3-O-Glucoside }\end{array}$} & \multicolumn{2}{|c|}{ Total } \\
\hline FA5 & 4.67 & A & 4.51 & A & 3.89 & $\mathrm{~A}$ & 0.78 & $\mathrm{~A}$ & 0.72 & & 0.68 & B & 0.68 & & 0.70 & & 12.12 & A \\
\hline CA & 3.83 & B & 3.47 & B & 3.69 & B & 0.79 & A & 0.73 & & 0.68 & B & 0.69 & & 0.69 & & 11.10 & B \\
\hline $\mathrm{CL}$ & 4.69 & A & 4.69 & A & 3.92 & A & 0.75 & B & 0.73 & & 0.69 & $\mathrm{AB}$ & 0.70 & & 0.71 & & 12.18 & A \\
\hline VK & 3.55 & B & 3.32 & B & 3.61 & B & 0.79 & A & 0.73 & & 0.70 & A & 0.68 & & 0.68 & & 10.73 & B \\
\hline$p$-value & $* * *$ & & $* * *$ & & $* *$ & & $* * *$ & & ns & & $* *$ & & ns & & ns & & $* * *$ & \\
\hline $\begin{array}{c}\text { Sampling } \\
\text { January }\end{array}$ & 3.66 & C & 3.01 & $\mathrm{C}$ & 3.47 & C & 0.74 & C & 0.69 & B & 0.67 & $\mathrm{D}$ & 0.64 & B & 0.65 & $\mathrm{D}$ & 10.51 & C \\
\hline February & 4.50 & $\mathrm{~B}$ & 4.08 & B & 3.68 & B & 0.76 & B & 0.71 & B & 0.68 & $\mathrm{C}$ & 0.64 & B & 0.67 & C & 11.65 & B \\
\hline March & 5.06 & A & 4.75 & A & 3.76 & B & 0.79 & B & 0.74 & A & 0.70 & B & 0.72 & A & 0.71 & B & 12.47 & A \\
\hline April & 3.52 & C & 4.15 & B & 4.20 & A & 0.82 & A & 0.76 & A & 0.71 & A & 0.73 & A & 0.77 & A & 11.51 & B \\
\hline$p$-value & $* * *$ & & $* * *$ & & $* * *$ & & $* * *$ & & $* * *$ & & $* * *$ & & $* * *$ & & $* * *$ & & $* * *$ & \\
\hline \multicolumn{19}{|l|}{ Year } \\
\hline 2017 & 4.48 & A & 3.43 & B & 3.78 & & 0.79 & A & 0.75 & A & 0.70 & A & 0.69 & & 0.71 & & 11.89 & A \\
\hline 2018 & 3.90 & B & 4.56 & A & 3.77 & & 0.76 & B & 0.70 & B & 0.68 & B & 0.67 & & 0.69 & & 11.18 & B \\
\hline$p$-value & $* * *$ & & $* * *$ & & ns & & $* *$ & & $* * *$ & & $* * *$ & & ns & & ns & & $* * *$ & \\
\hline
\end{tabular}

Mean values with different letters in the same column present significant differences. Significant level: ns $=$ not significant. ${ }^{*}=p<0.05 .{ }^{* *}=p<0.01 .{ }^{* * *}=p<0.001$. Values are expressed

as means of rootstocks, sampling date, and year. 


\subsubsection{Antioxidant Activity}

Table 4 shows the results of the ABTS, DPPH, and ORAC assays. In general, similar trends of antioxidant activity were found for each cultivar. However, the results for the 'Sanguinelli' samples were $40 \%$ higher than for the 'Salustiana' ones. Those results could be explained by the fact that the 'Sanguinelli' samples had a higher concentration of ascorbic acid and by their ability to synthetize and accumulate anthocyanins, which play an important role in the antioxidant activity of fruits $[24,59]$.

Table 4. Effect of rootstock, sampling date, and year on antioxidant activity (ABTS, DPPH, and ORAC) in 'Salustiana' and 'Sanguinelli' cultivars. ABTS and DPPH are expressed in mg TE/100 g FW and ORAC in $\mu \mathrm{M}$ TE/100 g FW.

\begin{tabular}{|c|c|c|c|c|c|c|}
\hline & \multicolumn{2}{|c|}{ ABTS } & \multicolumn{2}{|c|}{ DPPH } & \multicolumn{2}{|c|}{ ORAC } \\
\hline \multicolumn{7}{|c|}{ ROOTSTOCK } \\
\hline FA5 & 97.975 & $\mathrm{~A}$ & 119.52 & A & 1850.0 & $\mathrm{~A}$ \\
\hline CA & 91.772 & $\mathrm{~B}$ & 113.45 & B & 1800.9 & B \\
\hline CL & 85.643 & $\mathrm{C}$ & 123.47 & $\mathrm{~A}$ & 1751.1 & $\mathrm{C}$ \\
\hline VK & 86.482 & $\mathrm{C}$ & 112.27 & B & 1706.9 & $\mathrm{C}$ \\
\hline$p$-value & $* * *$ & & $* * *$ & & $* * *$ & \\
\hline \multicolumn{7}{|l|}{ SAMPLING } \\
\hline December & 63.52 & $\mathrm{D}$ & 99.82 & $\mathrm{D}$ & 1234.8 & $\mathrm{C}$ \\
\hline January & 86.94 & $\mathrm{C}$ & 110.10 & $\mathrm{C}$ & 1870.3 & B \\
\hline February & 105.89 & A & 119.26 & $\mathrm{~B}$ & 1962.2 & $\mathrm{~A}$ \\
\hline March & 94.58 & $\mathrm{~B}$ & 133.87 & A & 1993.8 & $\mathrm{~A}$ \\
\hline April & 101.42 & A & 122.84 & B & 1825.2 & B \\
\hline$p$-value & $* * *$ & & $* * *$ & & $* * *$ & \\
\hline \multicolumn{7}{|l|}{ YEAR } \\
\hline 2017 & 88.510 & B & 115.84 & & 1676.3 & $\mathrm{~B}$ \\
\hline 2018 & 92.426 & $\mathrm{~A}$ & 118.52 & & 1878.2 & A \\
\hline$p$-value & * & & ns & & $* * *$ & \\
\hline \multicolumn{7}{|c|}{ 'SANGUINELLI' } \\
\hline \multicolumn{7}{|c|}{ ROOTSTOCK } \\
\hline FA5 & 130.45 & A & 156.01 & $\mathrm{~A}$ & 2963.3 & $\mathrm{~A}$ \\
\hline CA & 111.49 & $\mathrm{~B}$ & 139.33 & $\mathrm{~B}$ & 2583.1 & B \\
\hline CL & 125.88 & A & 153.77 & A & 2985.0 & A \\
\hline VK & 116.30 & B & 140.24 & B & 2584.9 & B \\
\hline$p$-value & $* * *$ & & $* * *$ & & $* * *$ & \\
\hline \multicolumn{7}{|l|}{ SAMPLING } \\
\hline January & 97.95 & $\mathrm{C}$ & 129.61 & $\mathrm{C}$ & 2617.6 & B \\
\hline February & 124.99 & $\mathrm{~B}$ & 152.16 & B & 2772.7 & $\mathrm{AB}$ \\
\hline March & 132.48 & $\mathrm{~A}$ & 160.63 & $\mathrm{~A}$ & 2871.3 & A \\
\hline April & 128.69 & $\mathrm{AB}$ & 146.97 & B & 2854.7 & $\mathrm{~A}$ \\
\hline$p$-value & $* * *$ & & $* * *$ & & $*$ & \\
\hline \multicolumn{7}{|l|}{ YEAR } \\
\hline 2017 & 117.04 & B & 143.07 & B & 2613.0 & B \\
\hline 2018 & 125.01 & A & 151.61 & $\mathrm{~A}$ & 2945.1 & A \\
\hline$p$-value & $* * *$ & & $* * *$ & & $* * *$ & \\
\hline
\end{tabular}

Mean values with different letters in the same column present significant differences. Significant level: $\mathrm{ns}=$ not significant. ${ }^{*}=p<0.05 .{ }^{* *}=p<0.01 .{ }^{* * *}=p<0.001$. TE: Trolox equivalent. Values are expressed as means of rootstocks, sampling date, and year.

Regarding the rootstocks, the 'Salustiana' and 'Sanguinelli' orange fruits grafted on FA5 showed the highest levels of antioxidant capacity with the three methods under study (Table 4). Besides, differences in the cultivar-rootstock interaction were observed in the results of antioxidant 
activity for CL and CA. 'Salustiana' presented better results on CA, whilst the CL and FA5 samples presented the highest values in the 'Sanguinelli' oranges (Table 4). These results were related to lower concentrations of organic acids and phenolic compounds (Tables 1 and 2).

Changes in the antioxidant activity were observed in both orange cultivars during the sampling period (Table 4). For 'Salustiana', the highest values were observed for the samples harvested from February, while the peak antioxidant activity for the 'Sanguinelli' cultivar was found in the samples harvested from March. These data were linked to the fact that higher concentrations of phenolic compounds were observed in those harvesting dates (Tables 2 and 3).

Concerning the inter-year harvest period, the highest antioxidant activity was found for the second year in both cultivars, in line with the concentration of organic acids and phenolic compounds (Tables 1-3). This behavior could be explained by the more stressful conditions of the second harvesting period with lower (mean) precipitations, slightly higher (mean) temperature, lower (mean) relative humidity, higher (mean) solar radiation, and higher (mean) evapotranspiration (Table S2).

\subsection{Evaluation of Bioactive Compounds in the Hydrophobic Extracts}

\subsubsection{Total Carotenoids}

The total carotenoids concentration found in the 'Salustiana' and 'Sanguinelli' samples ranged from 0.45 to $0.63 \mathrm{mg} / 100 \mathrm{~g}$ FW (Table 5), in agreement with the concentrations reported in the literature $[17,26]$. Carotenoid content is known to be higher in the peel than in the pulp, reaching the $70 \%$ of the total [17]. We observed an impact of the rootstocks on this parameter. The samples from 'Salustiana' grafted on FA5 and CL obtained the highest concentration of total carotenoids, whilst CA obtained the highest values for the samples from the 'Sanguinelli' cultivar.

Table 5. Effect of rootstock, sampling date, and year on total carotenoids and antioxidant activity (ABTS-L) in 'Salustiana' and 'Sanguinelli' cultivars. ABTS-L is expressed in mg TE/100 g FW and total carotenoids in $\mathrm{mg} \beta \mathrm{C} / 100 \mathrm{~g}$ FW.

\begin{tabular}{ccccccccc}
\hline & \multicolumn{3}{c}{ 'SALUSTIANA' } & \multicolumn{5}{c}{ 'SANGUINELLI' } \\
\hline & \multicolumn{1}{c}{ Total Carotenoids } & ABTS-L & Total Carotenoids & ABTS-L \\
\hline ROOTSTOCK & & & & & & & & \\
FA5 & 0.61 & $\mathrm{~A}$ & 29.60 & $\mathrm{~A}$ & 0.52 & $\mathrm{~B}$ & 23.71 & $\mathrm{~A}$ \\
CA & 0.54 & $\mathrm{~B}$ & 29.66 & $\mathrm{~A}$ & 0.56 & $\mathrm{~A}$ & 19.77 & $\mathrm{C}$ \\
CL & 0.63 & $\mathrm{~A}$ & 27.94 & $\mathrm{~B}$ & 0.55 & $\mathrm{~B}$ & 22.57 & $\mathrm{~A}$ \\
VK & 0.50 & $\mathrm{C}$ & 28.26 & $\mathrm{AB}$ & 0.46 & $\mathrm{C}$ & 21.01 & $\mathrm{~B}$ \\
$\boldsymbol{p}$-value & $* * *$ & & $*$ & & $* * *$ & & $* * *$ & \\
\hline SAMPLING & & & & & & & & \\
December & 0.60 & $\mathrm{~A}$ & 30.35 & $\mathrm{~A}$ & & & & \\
January & 0.61 & $\mathrm{~A}$ & 30.33 & $\mathrm{~A}$ & 0.61 & $\mathrm{~A}$ & 27.14 & $\mathrm{~A}$ \\
February & 0.48 & $\mathrm{C}$ & 27.42 & $\mathrm{~B}$ & 0.50 & $\mathrm{C}$ & 22.49 & $\mathrm{~B}$ \\
March & 0.55 & $\mathrm{~B}$ & 28.17 & $\mathrm{~B}$ & 0.57 & $\mathrm{~B}$ & 20.62 & $\mathrm{C}$ \\
April & 0.61 & $\mathrm{~A}$ & 28.08 & $\mathrm{~B}$ & 0.44 & $\mathrm{D}$ & 16.81 & $\mathrm{D}$ \\
$\boldsymbol{p}$-value & $* * *$ & & $* * *$ & & $* * *$ & & $* * *$ & \\
\hline YEAR & & & & & & & & \\
$\mathbf{2 0 1 7}$ & 0.57 & & 26.87 & $\mathrm{~B}$ & 0.64 & $\mathrm{~A}$ & 22.01 & \\
$\mathbf{2 0 1 8}$ & 0.57 & & 30.86 & $\mathrm{~A}$ & 0.43 & $\mathrm{~B}$ & 21.52 & \\
$\boldsymbol{p}$-value & $\mathrm{ns}$ & & $* * *$ & & $* * *$ & & $\mathrm{~ns}$ & \\
\hline
\end{tabular}

Mean values with different letters in the same column present significant differences. Significant level: $\mathrm{ns}=$ not significant. $^{*}=p<0.05{ }^{* *}=p<0.01 .{ }^{* * *}=p<0.001$. TE: Trolox equivalent. $\beta C$ : $\beta$-carotene equivalent. Values are expressed as means of rootstocks, sampling date, and year.

We observed changes in the concentration of total carotenoids during the harvesting period. The lowest concentrations were found for the samples harvested during February and March for the 'Salustiana' cultivar. On the other hand, the highest content of carotenoids for the 'Sanguinelli' cultivar 
samples was found at the beginning of the harvesting period (January), decreasing until the end of the season. This trend was also observed in the 'Sanguinelli' cultivar by Cebadera-Miranda et al. [26].

Regarding the inter-year harvest period, a marked decrease was observed in the concentration of total carotenoids in the 'Sanguinelli' oranges in the second year, while we did not observe significant differences for the 'Salustiana' cultivar samples.

\subsubsection{Antioxidant Activity}

Table 5 displays the results of antioxidant activity determined in the lipophilic fraction for the 'Salustiana' and 'Sanguinelli' samples. Considering the rootstocks, we observed different trends between the 'Sanguinelli' and 'Salustiana' oranges. For the 'Salustiana' cultivar, the samples from the CL rootstock presented lower values than those from FA5 and CA. While for the 'Sanguinelli' cultivar, the samples with highest antioxidant activity were the ones from the FA5 and CL rootstocks.

If we take into consideration the total carotenoid content, we did not observe a correlation between both parameters. The different results observed and the non-correlation may be linked to the contribution of other antioxidant compounds in the hydrophobic fraction, such as tocopherols [60,61].

Moreover, the level of antioxidant activity decreased during the sampling period in both cultivars.

Concerning the harvesting year, the 'Sanguinelli' oranges did not show significant differences in antioxidant activity between harvesting years, whilst the 'Salustiana' oranges presented a significant increase in its ABTS-L concentration in 2018.

\subsection{Multivariate Statistical Analysis}

Finally, a multivariate analysis was performed to evaluate the effect of rootstocks on the concentration of bioactive compounds in both cultivars studied. Due to the paired multivariate data structure (time series of harvesting period), a multilevel partial least squares discriminant analysis (ML-PLS-DA) was fitted to the most discriminative variables, which were previously selected using an iterative variable reduction procedure. We focused on the effect of different rootstocks regardless of the harvesting period. The model built for the 'Salustiana' oranges was optimized for three components and a satisfactory BER of 0.25 was obtained. Scores and loadings were plotted in the subspace spanned by the first two latent variables. The selected variables were ascorbic acid, fumaric acid, DPPH, narirutin, didymin, and total carotenoids. The first two latent variables accounted for $54 \%$ of the total variability. The ML-PLS-DA scores showed a clear discrimination among the rootstocks evaluated (Figure 1A). The main source of variability was accounted for by the latent variable 1. Thus, positive loadings values were correlated to FA5 and CL, whilst CA and VK were related to negative values (Figure 1A,B). The loadings plot shows that all the selected variables had a positive correlation to FA5 and CL (Figure 1B). Moreover, these rootstocks were further discriminated on the second latent variable (Figure 1B). Thus, FA5 was mainly related to increases in the concentration of ascorbic acid, while CL was correlated to didymin. Thus, the final concentration of these compounds was highly related to the rootstock where the oranges were grafted. In general, this ML-PLS-DA showed that the 'Salustiana' cultivar grafted on FA5 or CL increased the concentrations of several bioactive compounds, such as ascorbic acid, didymin, or narirutin, and improved the antioxidant capacity (DPPH) of orange fruits.

The same procedure was followed to discriminate the 'Sanguinelli' samples on the basis of the rootstocks evaluated. The final ML-PLS-DA model built after the variable reduction was optimized for two components and again a satisfactory BER of 0.25 was obtained. The first two latent variables accounted for $40 \%$ of the total variability. The ML-PLS-DA scores show a clear discrimination among the four rootstocks evaluated (Figure 2A). The loadings plot (Figure 2B) shows the compounds responsible for the class separation. Thus, VK was related to cyanidin 3-O-(6-acetyl) glucoside and delphinidin 3-O-glucoside, while CA was associated with cyanidin 3,5-diglucoside. FA5 and CL were correlated to a higher number of compounds. CL was mainly related to didymin, cyanidin 3-O-glucoside, and ORAC, while FA5 was linked to ascorbic acid, 
vicenin-2, and narirutin, among others. Specifically, most anthocyanin compounds were employed in the model to discriminate between rootstocks. This may be due to the fact that rootstocks are a significant factor in the synthesis and accumulation of different types of anthocyanin [56,62]. A positive trend was observed for most bioactive compounds in the 'Sanguinelli' cultivar samples grafted on FA5 or CL, such as organic acids (ascorbic acid, malic acid, and citric acid), phenolic compounds (didymin, narirutin, and vicenin-2), anthocyanin compounds (cyanidin 3-O-glucoside and cyanidin 3-O-(6"-acetyl) glucoside), and antioxidant activity (ORAC and DPPH).

A)

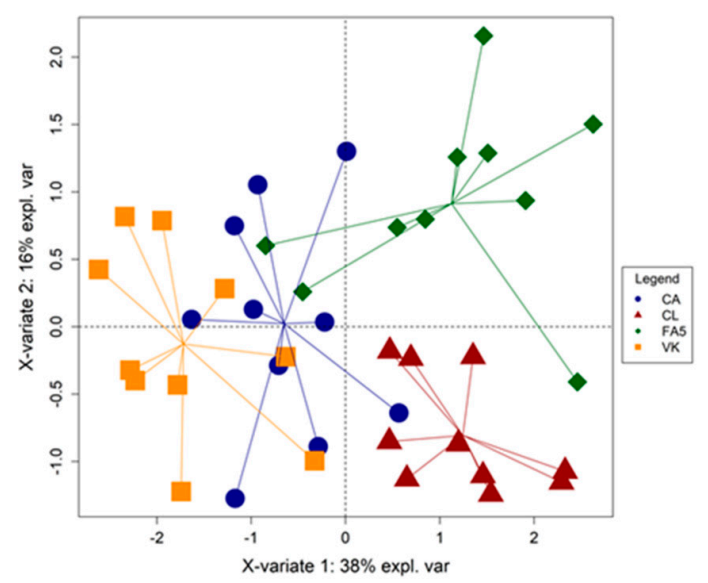

B)

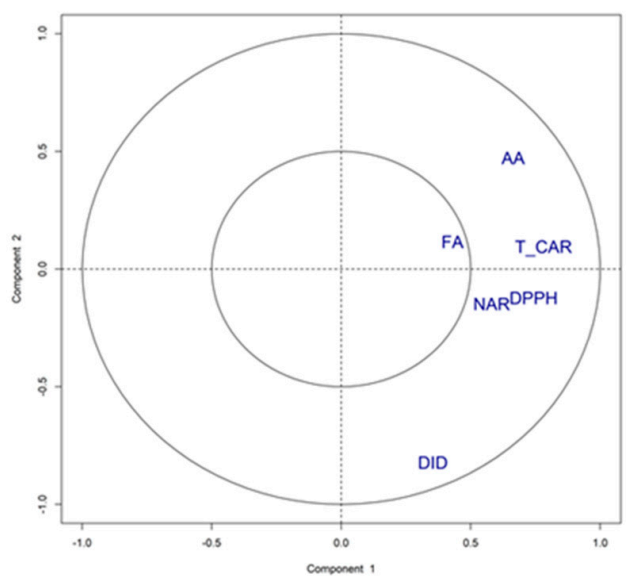

Figure 1. (A) Multilevel partial least squares discriminant analysis (ML-PLS-DA) scores plot of two first components performed on 'Salustiana' orange samples to evaluate the rootstock effects. Color and figure indicate the rootstocks: red triangles for 'Cleopatra mandarin' (CL), blue circles for Carrizo citrange (CA), yellow square for Citrus volkameriana (VK), and green diamond for Forner-Alcaide no.5 (FA5). (B) ML-PLS-DA loadings plot of the compounds selected in the iteration procedure in 'Salustiana' orange samples. Abbreviations: AA: Ascorbic acid, FA: Formic acid, T_CAR: Total carotenoids, NAR: Narirutin, DID: didymin.

A)

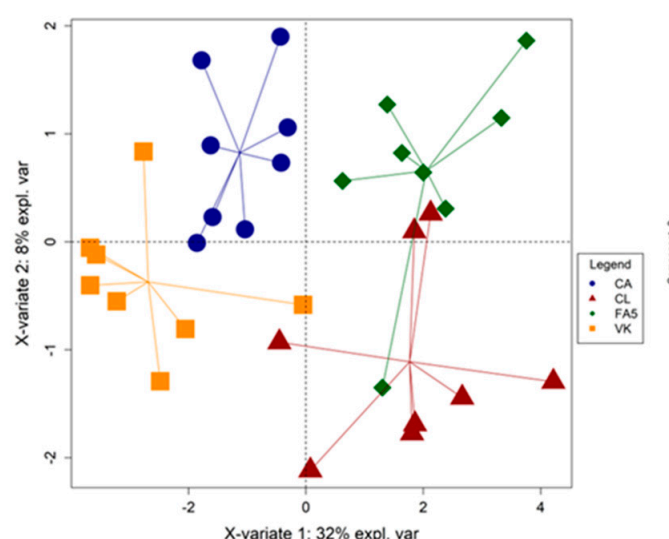

B)

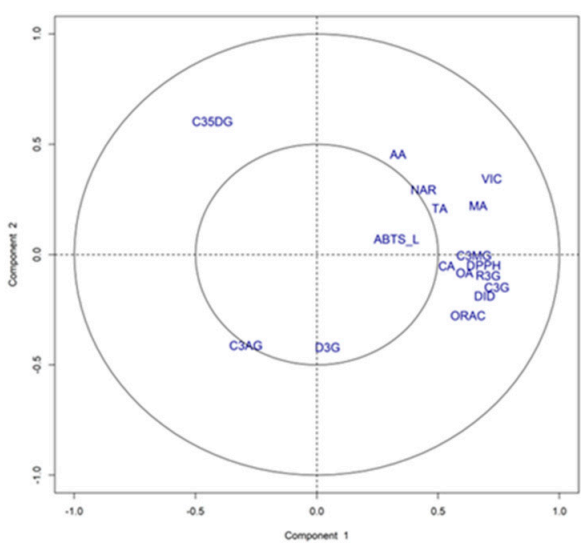

Figure 2. (A) ML-PLS-DA scores plot of two first components performed on 'Sanguinelli' orange samples to evaluate the rootstock effects. Color and figure indicate the rootstocks: red triangles for 'Cleopatra mandarin' (CL), blue circles for Carrizo citrange (CA), yellow square for Citrus volkameriana (VK), and green diamond for Forner-Alcaide no.5 (FA5). (B) ML-PLS-DA loadings plot of the compounds selected in the iteration procedure in 'Sanguinelli' orange samples. Abbreviations: AA: Ascorbic acid, TA: Tartaric acid, MA: Malic acid, CA: Citric acid, OA: Oxalic acid, NAR: Narirutin, DID: didymin, VIC:Vicenin-2, C3G: Cyanidin 3-O-glucoside, C3MG: Cyanidin 3-O-(6"-malonyl) glucoside, C35DG: Cyanidin 3,5-O-diglucoside, C3AG: Cyanidin 3-O-(6"-acetyl) glucoside, C3R: Cyanidin 3-O-rutinoside, D3G: Delphinidin 3-O-glucoside. 


\section{Conclusions}

This study performed an evaluation of the bioactive compounds in two orange cultivars, 'Salustiana' and 'Sanguinelli', on four different citrus rootstocks: Forner-Alcaide no. 5, 'Cleopatra mandarin', Citrus volkameriana, and Carrizo citrange.

The rootstocks under study were observed to have a strong influence on the bioactive compounds and antioxidant activity. In this sense, Forner-Alcaide no. 5, followed by 'Cleopatra mandarin', had the highest values for antioxidant activity in both cultivars. These results highlight that Forner-Alcaide no. 5 rootstock affected positively the phenolic and organic acid composition and the antioxidant capacity of 'Sanguinelli' and 'Salustiana' orange cultivars, and is therefore a good option for the sector taking into consideration its health-promoting properties.

Regarding the effect of the harvesting period, the maximum value for carotenoids and organic acids (mainly critic acid) was at the beginning of the season, while the phenolic compounds and antioxidant activity reached their highest levels between February and April.

Concerning the harvesting year, although variable results were found for most of parameters evaluated, the antioxidant activity was higher in the second year in both cultivars. This information may be useful for the juice industry as a starting point for the development of high-quality orange juices with significant levels of bioactive compounds.

Supplementary Materials: The following are available online at http://www.mdpi.com/2227-9717/8/10/1212/s1, Table S1: Characteristics of rootstocks: horticultural traits and tolerance grade of abiotic and biotic stress. Table S2: Climatic conditions of the geographical area. Table S3: Fruit quality of 'Salustiana' and 'Sanguinelli' oranges on 4 rootstocks: Diameter, \% of juice and total soluble solid ( ${ }^{\circ}$ Brix). Table S4: Identification of anthocyanin compounds in 'Sanguinelli' cultivar in positive ionization mode by HPLC-HRMS.

Author Contributions: Conceptualization, J.L.O.-D., G.P.-C., J.M.M.-R. (José M. Moreno-Rojas), A.H. and F.J.A.-A.; Methodology, J.L.O.-D., G.P.-C. and J.M.M.-R. (José M. Moreno-Rojas); Validation, J.L.O.-D., G.P.-C. and J.M.M.-R. (José M. Moreno-Rojas); Formal Analysis, J.L.O.-D., J.M.M.-R. (José M. Moreno-Rojas), A.H. and F.J.A.-A.; Investigation J.L.O.-D., G.P.-C, J.M.M.-R. (José M. Muñoz-Redondo), J.M.M.-R. (José M. Moreno-Rojas), E.R.-R., A.H. and F.J.A.-A.; Resources, J.L.O.-D., G.P.-C, J.M.M.-R. (José M. Muñoz-Redondo), J.M.M.-R. (José M. Moreno-Rojas), A.H. and F.J.A.-A.; Data Curation, J.L.O.-D., J.M.M.-R. (José M. Muñoz-Redondo) and J.M.M.-R. (José M. Moreno-Rojas); Writing—Original Draft Preparation, J.L.O.-D., J.M.M.-R. (José M. Moreno-Rojas) and A.H.; Writing-Review and Editing, J.L.O.-D., G.P.-C, J.M.M.-R. (José M. Muñoz-Redondo), J.M.M.-R. (José M. Moreno-Rojas), A.H. and F.J.A.-A.; Supervision, J.M.M.-R. (José M. Muñoz-Redondo) and F.J.A.-A.; Project Administration, A.H., J.M.M.-R. (José M. Muñoz-Redondo) and F.J.A.-A. All authors have read and agreed to the published version of the manuscript.

Funding: This research was funded by the project Network of Experimentation and Transfer in Andalusian Citrus, which was cofinanced ( $80 \%$ ) by the European Regional Development Fund within the FEDER Operational Program of Andalusia 2014-2020.

Acknowledgments: The authors wish to thank the project Network of Experimentation and Transfer in Andalusian Citrus (TRA201600.1), which was co-financed (80\%) by the European Regional Development Fund within the FEDER Operational Program of Andalusia 2014-2020. J.L.O-D and J.M.M-Re. were granted a research contract funded at Andalusian Institute of Agricultural and Fisheries Research and Training (IFAPA), within the National Youth Guarantee System funded through the European Social Fund (ESF) and the Youth Employment Initiative (YEI). G.P.C. was supported by a research contract funded by IFAPA and ESF (03/2014 to 03/2017) and a postdoctoral research contract "Juan de la Cierva-Incorporación" funded by the Spanish Ministry of Economy and Competitiveness (FJCI-2015-26433).

Conflicts of Interest: The authors declare no conflict of interest.

\section{References}

1. Velázquez-Estrada, R.; Chávez-Ocegueda, J.; Hernández-Herrero, M.; Roig-Sagués, A.X. Orange Juice. In Handbook of Functional Beverages and Human Health, 1st ed.; Shahidi, F., Alasalvar, C., Eds.; CRC Press: Boca Raton, FL, USA, 2016; pp. 423-437.

2. Arena, E.; Guarrera, N.; Campisi, S.; Nicolosi Asmundo, C. Comparison of odour active compounds detected by gas-chromatography- olfactometry between hand-squeezed juices from different orange varieties. Food Chem. 2006, 98, 59-63. [CrossRef] 
3. Cuevas, F.J.; Pereira-Caro, G.; Moreno-Rojas, J.M.; Muñoz-Redondo, J.M.; Ruiz-Moreno, M.J. Assessment of premium organic orange juices authenticity using HPLC-HR-MS and HS-SPME-GC-MS combining data fusion and chemometrics. Food Control 2017, 82, 203-211. [CrossRef]

4. Del Caro, A.; Piga, A.; Vacca, V.; Agabbio, M. Changes of flavonoids, vitamin C and antioxidant capacity in minimally processed citrus segments and juices during storage. Food Chem. 2004, 84, 99-105. [CrossRef]

5. Halliwell, B. Free radicals and antioxidants-Quo vadis? Trends Pharmacol. Sci. 2011, 32, 125-130. [CrossRef]

6. Del Rio, D.; Rodriguez-Mateos, A.; Spencer, J.P.E.; Tognolini, M.; Borges, G.; Crozier, A. Dietary (Poly)phenolics in Human Health: Structures, Bioavailability, and Evidence of Protective Effects Against Chronic Diseases. Antioxid. Redox Signal. 2013, 18, 1818-1892. [CrossRef]

7. Ordóñez, J.L.; Pereira-Caro, G.; Ludwig, I.; Muñoz-Redondo, J.M.; Ruiz-Moreno, M.J.; Crozier, A.; Moreno-Rojas, J.M. A critical evaluation of the use of gas chromatography- and high performance liquid chromatography-mass spectrometry techniques for the analysis of microbial metabolites in human urine after consumption of orange juice. J. Chromatogr. A 2018, 1575, 100-112. [CrossRef] [PubMed]

8. Sicari, V.; Dorato, G.; Giuffrè, A.M.; Rizzo, P.; Albunia, A.R. The effect of different packaging on physical and chemical properties of oranges during storage. J. Food Process. Preserv. 2017, 41, e13168. [CrossRef]

9. Kelebek, H.; Selli, S.; Canbas, A.; Cabaroglu, T. HPLC determination of organic acids, sugars, phenolic compositions and antioxidant capacity of orange juice and orange wine made from a Turkish cv. Kozan. Microchem. J. 2009, 91, 187-192. [CrossRef]

10. Pereira-Caro, G.; Borges, G.; van der Hooft, J.; Clifford, M.N.; Del Rio, D.; Lean, M.E.; Roberts, S.A.; Kellerhals, M.B.; Crozier, A. Orange juice (poly)phenols are highly bioavailable in humans. Am. J. Clin. Nutr. 2014, 100, 1378-1384. [CrossRef]

11. Kay, C.D.; Pereira-Caro, G.; Ludwig, I.A.; Clifford, M.N.; Crozier, A. Anthocyanins and Flavanones Are More Bioavailable than Previously Perceived: A Review of Recent Evidence. Annu. Rev. Food Sci. Technol. 2017, 8 , 1-26. [CrossRef]

12. De la Rosa, J.D.P.; Ruiz-Palomino, P.; Arriola-Guevara, E.; García-Fajardo, J.; Sandoval, G.; Guatemala-Morales, G.M. A green process for the extraction and purification of hesperidin from mexican lime peel (Citrus aurantifolia Swingle) that is extendible to the Citrus genus. Processes 2018, 6, 266. [CrossRef]

13. Meneguzzo, F.; Ciriminna, R.; Zabini, F.; Pagliaro, M. Review of evidence available on hesperidin-rich products as potential tools against COVID-19 and hydrodynamic cavitation-based extraction as a method of increasing their production. Processes 2020, 8, 549. [CrossRef]

14. Legua, P.; Forner, J.B.; Hernández, F.; Forner-Giner, M.A. Physicochemical properties of orange juice from ten rootstocks using multivariate analysis. Sci. Hortic. 2013, 160, 268-273. [CrossRef]

15. Abeysinghe, D.C.; Li, X.; Sun, C.; Zhang, W.S.; Zhou, C.H.; Chen, K.S. Bioactive compounds and antioxidant capacities in different edible tissues of citrus fruit of four species. Food Chem. 2007, 104, 1338-1344. [CrossRef]

16. Alquezar, B.; Rodrigo, M.J.; Zacarías, L. Carotenoid Biosynthesis and its Regulation in Citrus Fruits. Tree For. Sci. Biotech. 2008, 2, 23-37.

17. Lado, J.; Gambetta, G.; Zacarias, L. Key determinants of citrus fruit quality: Metabolites and main changes during maturation. Sci. Hortic. 2018, 233, 238-248. [CrossRef]

18. Hervalejo, A.; Suarez, M.P.; Moreno-Rojas, J.M.; Arenas-Arenas, F.J. Overall Fruit Quality of "Lane Late" Orange on Sub-Standard and Semi-Dwarfing Rootstocks. J. Agric. Sci. Tech. 2020, 22, 235-246.

19. Arenas-Arenas, F.J.; González-Chimeno, A.B.; Romero-Rodríguez, E.; Hervalejo, A. Characterization of different cultivars of citrus fruit for juice in the south of Spain. Citrus Res. Tech. 2017, 38, 1-9. [CrossRef]

20. Gil-Izquierdo, A.; Gil, M.I.; Ferreres, F. Effect of Processing Techniques at Industrial Scale on Orange Juice Antioxidant and Beneficial Health Compounds. J. Agric. Food Chem. 2002, 50, 5107-5114. [CrossRef]

21. Torres, B.; Tiwari, B.K.; Patras, A.; Cullen, P.J.; Brunton, N.; O’Donnell, C.P. Stability of anthocyanins and ascorbic acid of high pressure processed blood orange juice during storage. Innov. Food Sci. Emerg. Technol. 2011, 12, 93-97. [CrossRef]

22. Zhang, J.; Yang, Z.; Liang, Y.; Zhang, L.; Ling, W.; Guo, C.; Liang, G.; Luo, G.; Ye, Q.; Zhong, B. Effects of postharvest time, heat treatment, $\mathrm{pH}$ and filtration on the limonin content in Newhall navel orange (Citrus sinensis Osbeck cv. Newhall) juice. Molecules 2018, 23, 2691. [CrossRef] [PubMed]

23. Romero-Rodríguez, E.; Hervalejo, A.; Castillo, C.I.; Arenas, F.J. Caracterización de distintas variedades de cítricos para la industria en el valle del Guadalquivir. Lev. Agríc. 2014, 242, 264-271. 
24. Kelebek, H.; Canbas, A.; Selli, S. Determination of phenolic composition and antioxidant capacity of blood orange juices obtained from cvs. Moro and Sanguinello (Citrus sinensis (L.) Osbeck) grown in Turkey. Food Chem. 2008, 107, 1710-1716. [CrossRef]

25. Le, X.T.; Huynh, M.T.; Pham, T.N.; Than, V.T.; Toan, T.Q.; Bach, L.G.; Trung, N.Q. Optimization of Total Anthocyanin Content, Stability and Antioxidant Evaluation of the Anthocyanin Extract from Vietnamese Carissa carandas L. Fruits. Processes 2019, 7, 468. [CrossRef]

26. Cebadera-Miranda, L.; Domínguez, L.; Dias, M.I.; Barros, L.; Ferreira, I.C.F.R.; Igual, M.; Martínez-Navarrete, N.; Fernández-Ruiz, V.; Morales, P.; Cámara, M. Sanguinello and Tarocco (Citrus sinensis [L.] Osbeck): Bioactive compounds and colour appearance of blood oranges. Food Chem. 2019, 270, 395-402. [CrossRef]

27. Cardeñosa, V.; Barros, L.; Barreira, J.C.M.; Arenas, F.; Moreno-Rojas, J.M.; Ferreira, I.C.F.R. Different Citrus rootstocks present high dissimilarities in their antioxidant activity and vitamins content according to the ripening stage. J. Plant Physiol. 2015, 174, 124-130. [CrossRef]

28. Romero-Rodríguez, E.; Calero-Velázquez, R.; Hervalejo, A.; Arenas-Arenas, F.J. Comportamiento agronómico de la variedad 'Sanguinelli' injertada sobre cuatro patrones de cítricos. Resultados sobre citrange Carrizo, mandarino 'Cleopatra', Citrus volkameriana y Forner-Alcaide no 5. Vida Rural 2018, 452, 44-49.

29. Forner-Giner, M.A.; Alcaide, A.; Primo-Millo, E.; Forner, J.B. Performance of "Navelina" orange on 14 rootstocks in Northern Valencia (Spain). Sci. Hortic. 2003, 98, 223-232. [CrossRef]

30. Doorenbos, J.; Pruitt, W. Crop Water Requirements; FAO Irrigation and Drainage Paper 24; Food and Agriculture Organization of the United Nations (FAO): Rome, Italy, 1977; p. 144.

31. Quinones, A.; Martinez-Alcantara, B.; Primo-Millo, E.; Legaz, F. Fertilizacion de los citricos en riego a goteo (I): N, P, K. Lev. Agríc. 2007, 389, 380-386.

32. Stinco, C.M.; Fernández-Vázquez, R.; Escudero-Gilete, M.L.; Heredia, F.J.; Meléndez-Martínez, A.J.; Vicario, I.M. Effect of orange juices processing on the color, particle size, and bioaccessibility of carotenoids. J. Agric. Food Chem. 2012, 60, 1447-1455. [CrossRef]

33. Cuevas, F.J.; Pradas, I.; Ruiz-Moreno, M.J.; Arroyo, F.T.; Perez-Romero, L.F.; Montenegro, J.C.; Moreno-Rojas, J.M. Effect of Organic and Conventional Management on Bio-Functional Quality of Thirteen Plum Cultivars (Prunus salicina Lindl.). PLoS ONE 2015, 10, e0136596. [CrossRef] [PubMed]

34. Re, R.; Pellegrini, N.; Proteggente, A.; Pannala, A.; Yang, M.; Rice-Evans, C. Antioxidant activity applying an improved ABTS radical cation decolorization assay. Free Radic. Biol. Med. 1999, 26, 1231-1237. [CrossRef]

35. Madrona, A.; Pereira-Caro, G.; Bravo, L.; Mateos, R.; Espartero, J.L. Preparation and antioxidant activity of tyrosyl and homovanillyl ethers. Food Chem. 2011, 129, 1169-1178. [CrossRef] [PubMed]

36. Sánchez-Moreno, C.; Larrauri, J.A.; Saura-Calixto, F. A procedure to measure the antiradical efficiency of polyphenols. J. Sci. Food Agric. 1998, 76, 270-276. [CrossRef]

37. Alzate T, L.M.; González, D.; Hincapié, S.; Cardona S, B.L.; Londoño-Londoño, J.; Jiménez-Cartagena, C. The profile of bioactive substances in ten vegetable and fruit by-products from a food supply chain in Colombia. Sustain. Prod. Consum. 2017, 9, 37-43. [CrossRef]

38. Hornedo-Ortega, R.; Álvarez-Fernández, M.A.; Cerezo, A.B.; Garcia-Garcia, I.; Troncoso, A.M.; Garcia-Parrilla, M.C. Influence of Fermentation Process on the Anthocyanin Composition of Wine and Vinegar Elaborated from Strawberry. J. Food Sci. 2017, 82, 364-372. [CrossRef]

39. Moreno-Ortega, A.; Pereira-Caro, G.; Ordóñez, J.L.; Muñoz-Redondo, J.M.; Moreno-Rojas, R.; Pérez-Aparicio, J.; Moreno-Rojas, J.M. Changes in the antioxidant activity and metabolite profile of three onion varieties during the elaboration of 'black onion'. Food Chem. 2020, 311, 125958. [CrossRef]

40. Rohart, F.; Gautier, B.; Singh, A.; Lê Cao, K.-A. mixOmics: An R package for 'omics feature selection and multiple data integration. PLoS Comput. Biol. 2017, 13, e1005752. [CrossRef]

41. Westerhuis, J.A.; van Velzen, E.J.J.; Hoefsloot, H.C.J.; Smilde, A.K. Multivariate paired data analysis: Multilevel PLSDA versus OPLSDA. Metabolomics 2010, 6, 119-128. [CrossRef]

42. Muñoz-Redondo, J.M.; Ruiz-Moreno, M.J.; Puertas, B.; Cantos-Villar, E.; Moreno-Rojas, J.M. Multivariate optimization of headspace solid-phase microextraction coupled to gas chromatography-mass spectrometry for the analysis of terpenoids in sparkling wines. Talanta 2019, 208, 120483. [CrossRef]

43. Emmanouilidou, M.G.; Kyriacou, M.C. Rootstock-modulated yield performance, fruit maturation and phytochemical quality of 'Lane Late' and 'Delta' sweet orange. Sci. Hortic. 2017, 225, 112-121. [CrossRef]

44. Cercós, M.; Soler, G.; Iglesias, D.J.; Gadea, J.; Forment, J.; Talón, M. Global analysis of gene expression during development and ripening of citrus fruit flesh. A proposed mechanism for citric acid utilization. Plant Mol. Biol. 2006, 62, 513-527. [CrossRef] [PubMed] 
45. Truffault, V.; Fry, S.C.; Stevens, R.G.; Gautier, H. Ascorbate degradation in tomato leads to accumulation of oxalate, threonate and oxalyl threonate. Plant J. 2017, 89, 996-1008. [CrossRef] [PubMed]

46. Melino, V.J.; Soole, K.L.; Ford, C.M. Ascorbate metabolism and the developmental demand for tartaric and oxalic acids in ripening grape berries. BMC Plant Biol. 2009, 9, 145. [CrossRef]

47. Ong, B.T.; Nazimah, S.A.H.; Osman, A.; Quek, S.Y.; Voon, Y.Y.; Hashim, D.M.; Chew, P.M.; Kong, Y.W. Chemical and flavour changes in jackfruit (Artocarpus heterophyllus Lam.) cultivar J3 during ripening. Postharvest Biol. Technol. 2006, 40, 279-286. [CrossRef]

48. Gattuso, G.; Barreca, D.; Gargiulli, C.; Leuzzi, U.; Caristi, C. Flavonoid Composition of Citrus Juices. Molecules 2007, 12, 1641-1673. [CrossRef] [PubMed]

49. Giuffrè, A.M.; Zappia, C.; Capocasale, M. Physicochemical stability of blood orange juice during frozen storage. Physicochemical stability of blood orange juice during frozen storage. Int. J. Food Prop. 2017, 20, 1930-1943.

50. Tomás-Barberán, F.A.; Clifford, M.N. Flavanones, chalcones and dihydrochalcones-Nature, occurrence and dietary burden. J. Sci. Food Agric. 2000, 80, 1073-1080. [CrossRef]

51. Nogata, Y.; Sakamoto, K.; Shiratsuchi, H.; Ishii, T.; Yano, M.; Ohta, H. Flavonoid Composition of Fruit Tissues of Citrus Species. Biosci. Biotechnol. Biochem. 2006, 70, 178-192. [CrossRef] [PubMed]

52. De Ancos, B.; Cilla, A.; Barberá, R.; Sánchez-Moreno, C.; Cano, M.P. Influence of orange cultivar and mandarin postharvest storage on polyphenols, ascorbic acid and antioxidant activity during gastrointestinal digestion. Food Chem. 2017, 225, 114-124. [CrossRef]

53. Feng, S.; Niu, L.; Suh, J.H.; Hung, W.L.; Wang, Y. Comprehensive metabolomics analysis of mandarins (Citrus reticulata) as a tool for variety, rootstock, and grove discrimination. J. Agric. Food Chem. 2018, 66, 10317-10326. [CrossRef] [PubMed]

54. Fattahi, J.; Hamidoghli, Y.; Fotouhi, R.; Ghasemnejad, M.; Bakhshi, D. Assessment of fruit quality and antioxidant activity of three citrus species during ripening. South-West. J. Hortic. Biol. Environ. 2011, 2, 113-128.

55. Fabroni, S.; Ballistreri, G.; Amenta, M.; Rapisarda, P. Anthocyanins in different citrus species: An UHPLCPDA-ESI/MSn-assisted qualitative and quantitative investigation. J. Sci. Food Agric. 2016, 96, 4797-4808. [CrossRef] [PubMed]

56. Lo Piero, A.R. The state of the art in biosynthesis of anthocyanins and its regulation in pigmented sweet oranges [(Citrus sinensis) L. Osbeck]. J. Agric. Food Chem. 2015, 63, 4031-4041. [CrossRef] [PubMed]

57. Dugo, P.; Mondello, L.; Morabito, D.; Dugo, G. Characterization of the anthocyanin fraction of sicilian blood orange juice by micro-HPLC-ESI/MS. J. Agric. Food Chem. 2003, 51, 1173-1176. [CrossRef] [PubMed]

58. Barbagallo, R.N.; Palmeri, R.; Fabiano, S.; Rapisarda, P.; Spagna, G. Characteristic of $\beta$-glucosidase from Sicilian blood oranges in relation to anthocyanin degradation. Enzym. Microb. Technol. 2007, 41, 570-575. [CrossRef]

59. Jayaprakasha, G.K.; Patil, B.S. In vitro evaluation of the antioxidant activities in fruit extracts from citron and blood orange. Food Chem. 2007, 101, 410-418. [CrossRef]

60. Cardeñosa, V.; Barreira, J.C.M.; Barros, L.; Arenas-Arenas, F.J.; Moreno-Rojas, J.M.; Ferreira, I.C.F.R. Variety and harvesting season effects on antioxidant activity and vitamins content of citrus sinensis macfad. Molecules 2015, 20, 8287-8302. [CrossRef]

61. Cebadera, L.; Dias, M.I.; Barros, L.; Fernández-Ruiz, V.; Cámara, R.M.; Del Pino, Á.; Santos-Buelga, C.; Ferreira, I.C.F.R.; Morales, P.; Cámara, M. Characterization of extra early Spanish clementine varieties (Citrus clementina hort ex tan) as a relevant source of bioactive compounds with antioxidant activity. Food 2020, 9, 642. [CrossRef]

62. Carmona, L.; Alquézar, B.; Marques, V.V.; Peña, L. Anthocyanin biosynthesis and accumulation in blood oranges during postharvest storage at different low temperatures. Food Chem. 2017, 237, 7-14. [CrossRef]

(C) 2020 by the authors. Licensee MDPI, Basel, Switzerland. This article is an open access article distributed under the terms and conditions of the Creative Commons Attribution (CC BY) license (http://creativecommons.org/licenses/by/4.0/). 